\title{
Responsiveness of the Spanish Version of Newcastle Stroke-Specific Quality of Life Measure (NEWSQOL)
}

\author{
Concepción Soto-Vidal ${ }^{1}$, Victoria Calvo-Fuente ${ }^{1, * \mathbb{D}}$, Alfonso Muriel-García ${ }^{1} \mathbb{D}$, Tomás Gallego-Izquierdo ${ }^{1}$, \\ Carlos González-Alted ${ }^{2}$ and Soraya Pacheco-da-Costa ${ }^{1}$ id
}

1 Department of Nursing and Physiotherapy, Universidad de Alcalá, 28871 Madrid, Spain; conchi.soto@uah.es (C.S.-V.); alfonso.muriel@uah.es (A.M.-G.); tomas.gallego@uah.es (T.G.-I.); soraya.pacheco@uah.es (S.P.-d.-C.)

2 Medical Director State Reference Center for Brain Damage Care, 28034 Madrid, Spain; cgonzaalted@imserso.es

* Correspondence: victoria.calvo@uah.es; Tel.: +34-918-854-845

Citation: Soto-Vidal, C.;

Calvo-Fuente, V.; Muriel-García, A.; Gallego-Izquierdo, T.;

González-Alted, C.;

Pacheco-da-Costa, S. Responsiveness of the Spanish Version of Newcastle Stroke-Specific Quality of Life Measure (NEWSQOL). Int. J. Environ. Res. Public Health 2021, 18, 10034. https://doi.org/10.3390/ ijerph181910034

Academic Editor: Paul B. Tchounwou

Received: 16 July 2021

Accepted: 16 September 2021

Published: 24 September 2021

Publisher's Note: MDPI stays neutral with regard to jurisdictional claims in published maps and institutional affiliations.

Copyright: (c) 2021 by the authors. Licensee MDPI, Basel, Switzerland. This article is an open access article distributed under the terms and conditions of the Creative Commons Attribution (CC BY) license (https:// creativecommons.org/licenses/by/ $4.0 /)$.
Abstract: Objective: To evaluate the responsiveness of the Spanish version of the Newcastle Strokespecific Quality of Life measure (NEWSQOL) to assess quality of life in Spanish people after suffering a stroke. Design: A prospective observational study was conducted to assess the responsiveness of the Spanish version of NEWSQOL. The sample contained 128 patients who filled in the questionnaires before and after a physical therapy intervention. The responsiveness was assessed with $p$-values using the effect size (ES) and the standardized response means (SRMs) of the change. Besides, two other external criteria were used to distinguish patients who improved with the treatment from those who remained stable. This classification was based on one functional independence measure (the Barthel Index) and one disability measure (the modified Rankin Scale). Results: There was a statistically significant correlation (Spearman's coefficient $=p<0.01$ ) between the domains of the Spanish version of NEWSQOL in relation to the Barthel Index and the modified Rankin Scale. All domains showed between marked-to-mild change responsiveness except sleep and relationships; mobility (ES 0.66 and SRM 0.92) and activities of daily living (ES 0.75 and SRM 0.87) were markedly responsive; communication (ES 0.38 and SRM 0.61) was moderately responsive; and pain, vision, cognition, feelings, emotions and fatigue were mildly responsive (ES 0.21-0.41 and SRM 0.23-0.44). Conclusion: The Spanish version of NEWSQOL shows between marked and mild responsiveness to measure the perception of QoL in post-stroke patients. Therefore, its use can be suitable for evaluation studies, clinical trials and clinical practice.

Keywords: quality of life; stroke; responsiveness; physical therapy; NEWSQOL

\section{Introduction}

The World Health Organization defines stroke as "the rapid onset of clinical symptoms of focal or global brain dysfunction, which lasts longer than $24 \mathrm{~h}$ or leads to death, with no other apparent cause than a vascular injury" [1]. The number of stroke patients around the world has increased considerably in recent decades [2], especially since the global pandemic started, where stroke arose as a complication of COVID-19, although up to now, its incidence remains unknown [3,4]. Clinical manifestations are wide and varied, including motor, sensory, perception and cognitive disturbances; urinary and faecal incontinence; swallowing and visual problems; and pain, communication and behavioural alterations [5-14]. Although motor disturbances might be responsible for a high rate of disability, sometimes patients report other important aspects [15], such as difficulties in performing activities of daily living (ADL), risk of falls and a negative impact on their quality of life (QoL) [16-21].

Health-related quality of life (HRQoL) measures have been of most importance, and it is essential to assess patients' perceptions. A valid way to measure such subjective 
sensations is through psychometrically validated questionnaires that, objectively, collect information on other aspects of the disease, its impact on the patient's QoL and changes after a therapeutic approach [22,23].

The Newcastle Stroke-specific Quality of Life measure (NEWSQOL) is a specific questionnaire to measure the QoL of patients who suffered a stroke. It was developed and validated by Buck et al. [24]. It is different from other questionnaires because it includes domains of vision, cognition and communication, and it can used for patients with ischaemic or haemorrhagic stroke and motor aphasia. In the Spanish version of NEWSQOL [25], the psychometric properties of feasibility, validity, reliability and ceiling and floor effects are tested. However, NEWSQOL responsiveness is not published at the moment, neither in the original version nor in the Spanish version.

Responsiveness is defined as the "ability to detect changes that are significant or clinically important" [26]. It is an essential psychometric property in any questionnaire in order to detect positive or negative changes that might occur after a therapeutic intervention or other changes regarding a disease, and should be considered a key feature of assessment instruments designed to measure longitudinal change over time $[27,28]$. Assessing the responsiveness of an instrument is of special importance, both in clinical practice and in research studies, to evaluate the effectiveness of health interventions.

Therefore, the aim of this study was to report the responsiveness of the Spanish version of NEWSQOL to assess the quality of life in Spanish post-stroke people who undergo physical therapy.

\section{Materials and Methods}

A multicenter longitudinal observational study was conducted. Patients who had survived a stroke were recruited by physical therapists from 3 different centres in Spain between September 2012 and December 2018: Ramon and Cajal Hospital, the Brain Damage State Centre (CEADAC) and the Institute of Neurological Diseases (IEN). The inclusion criteria were patients who had suffered a stroke and were older than 18 years and the time after stroke of 1 month to 2 years. The exclusion criteria were subjects who had serious or potentially terminal comorbidities, presented other neurological or neuromuscular diseases that had repercussions on their QoL, were diagnosed with serious psychiatric diseases, were dependent for ADL before the stroke or had moderate or severe cognitive deterioration according to Pfeiffer's questionnaire [29].

All participants signed a written informed consent form before their inclusion in the study, and the data collected from each participant were associated with a code for anonymity guarantee.

The study was approved by the Ramon and Cajal University Hospital Research Ethics Committee in Madrid, Spain (protocol no. 120/11).

The demographic data and clinical history of patients were collected at baseline. The Spanish version of the NEWSQOL questionnaire (Supplementary S1), the Barthel Index (BI) and the modified Rankin Scale (mRS) were fulfilled twice by neurological physical therapists: at baseline and at 6 months after a physical therapy intervention, which consisted of motor control techniques, 3 sessions per week, 40 min each session.

NEWSQOL includes 56 items divided into 11 domains: mobility (items 1-9), ADL/selfcare (items 10-17), pain/sensation (items 18-20), vision (items 21-22), cognition (items 23-27), communication (items 28-31), feelings (items 32-37), interpersonal relationships (items 38-43), emotions (items 44-47), sleep (items 48-53) and fatigue (items 54-56). Each item can be answered on four levels of involvement: none, a little, moderately or a lot. The minimum score for each item is 0 points (low effect), and the maximum is 3 points (maximum effect), and they are not significant individually. The results of each domain are obtained by the sum of the scores of the items; higher values indicate greater impact on the quality-of-life perception. The author of the original questionnaire does not recommend adding the scores obtained in the domains to achieve a global score [24] (Table 1). 
Table 1. Scoring NEWSQOL.

\begin{tabular}{|c|c|c|c|c|c|c|c|c|c|c|c|c|}
\hline Domains & Mobility & ADL/Self-Care & Pain/Sensation & Vision & Cognition & Communication & Feelings & IR & Emotion & Sleep & Fatigue & NEWSQOL \\
\hline \multirow[t]{8}{*}{ Items } & $1-9$ & $10-17$ & $18-20$ & $21-22$ & $23-27$ & $28-31$ & $32-37$ & $38-43$ & $44-47$ & $48-53$ & $54-56$ & \\
\hline & 1 & 1 & 1 & 1 & 1 & 1 & 1 & 1 & 1 & 1 & 1 & \\
\hline & 2 & 2 & 2 & 2 & 2 & 2 & 2 & 2 & 2 & 2 & 2 & \\
\hline & 3 & 3 & 3 & & 3 & 3 & 3 & 3 & 3 & 3 & 3 & \\
\hline & 5 & 5 & & & 5 & & 5 & 5 & & 5 & & \\
\hline & 6 & 6 & & & & & 6 & 6 & & 6 & & \\
\hline & 7 & 7 & & & & & & & & & & \\
\hline & 8 & 8 & & & & & & & & & & \\
\hline Range & $\begin{array}{c}9 \\
0-27\end{array}$ & $0-24$ & $0-9$ & $0-6$ & $0-15$ & $0-12$ & $0-18$ & $0-18$ & $0-12$ & $0-18$ & $0-9$ & No score \\
\hline
\end{tabular}

ADL: activities of daily living; IR: interpersonal relationships. None: 0; a little: 1; moderately: 2; a lot: 3. 
The mRS is used for measuring the degree of disability or dependence in ADL of people who have suffered a stroke. The scale is reported as ranging from 0 (no symptoms) to 6 (death), and it is valid, reliable and easy to use [30].

The $\mathrm{BI}$ is a generic instrument developed to assess functional independence in ADL, generally in post-stroke patients [31]. It is valid and reliable, and easy to use, and it shows better responsiveness than other generic scales for stroke patients [32]. It ranges from 0 to 100 points, and the better the score, the more independent the person [33].

To assess the responsiveness of a questionnaire, it is necessary to use some criteria to prove whether patients have experienced change throughout the study, and it is recommended to use independent criteria [34]. In this study, the change scores of the mRS and BI were used as two external anchor criteria. The first criterion was based on the change between categories in the mRS at the beginning and at the end of the 6 months of follow-up [35]. Improvement $=$ improvement of at least one level; stable $=$ unchanged; and impairment $=$ loss of at least one level were considered.

Regarding BI anchor criteria, we used the minimally clinically important difference (MCID) of 1.85 points estimated by Hsiech et al. [36]. The results were a reference value of 9.25 on a 100 point-scale. They were interpreted as follows: improvement $=$ increase of 9.25 points or more; deterioration $=$ decrease of 9.25 points or more; and stable $=$ change (increase/decrease) less than 9.25 points. No distinction was made between "some" and "big" changes. The average change was calculated as average change score seen in the cohort defined to be responders; minimally detectable change = equal to the upper value of the $95 \%$ confidence interval for average change scores seen in the cohort defined to be nonresponders; and change difference $=$ the difference of the average change score for responders and nonresponders.

Correlations between the score changes of the different measures were evaluated with Spearman's rank correlation coefficient. In addition, questionnaire responsiveness was evaluated using two statistical methods: the effect size (ES) and the change standardized response mean (SRM) in the scores at the assessments for each domain of the questionnaire. Baseline scores were compared with scores obtained 6 months later, using the Wilcoxon test because no normality score in the Shapiro test was found. The ES refers to the mean change in the score divided by the score domain standard deviation (SD) at baseline. The denominator standardizes the difference by transforming the absolute difference into baseline standard deviation units. The SRM is equivalent to the change in score over a period of time divided by the change in SD. Both the ES and the SRM were interpreted as follows: $<0.2$ as non-responsive, $0.2-0.5$ as mildly responsive, $0.51-0.7$ as moderately responsive and $\geq 0.7$ as markedly responsive to change [37].

The data was statistically analyzed using SPSS version 26 for Windows. The results were considered statistically significant for $p$-value $<0.05$ (two-tail test).

\section{Results}

A total of 159 subjects were recruited for the study, of which 128 subjects filled in the Spanish version of NEWSQOL in both assessments and were included for responsiveness validity of the questionnaire (Figure 1 ).

Table 2 shows the socio-demographic and clinical characteristics of the sample. Most of the subjects were middle-aged (49 years old) men (51.6\%) who were under sick leave $(68.0 \%)$ and had help from their families $(92.9 \%)$. Comorbidities in the study sample, such as hypertension $(31.4 \%)$, diabetes $(13.2 \%)$ and others $(23.2 \%)$, were common. The mean baseline score for the BI was 64.7 (31.2) and for the mRS was $4(2.5 ; 4)$. 


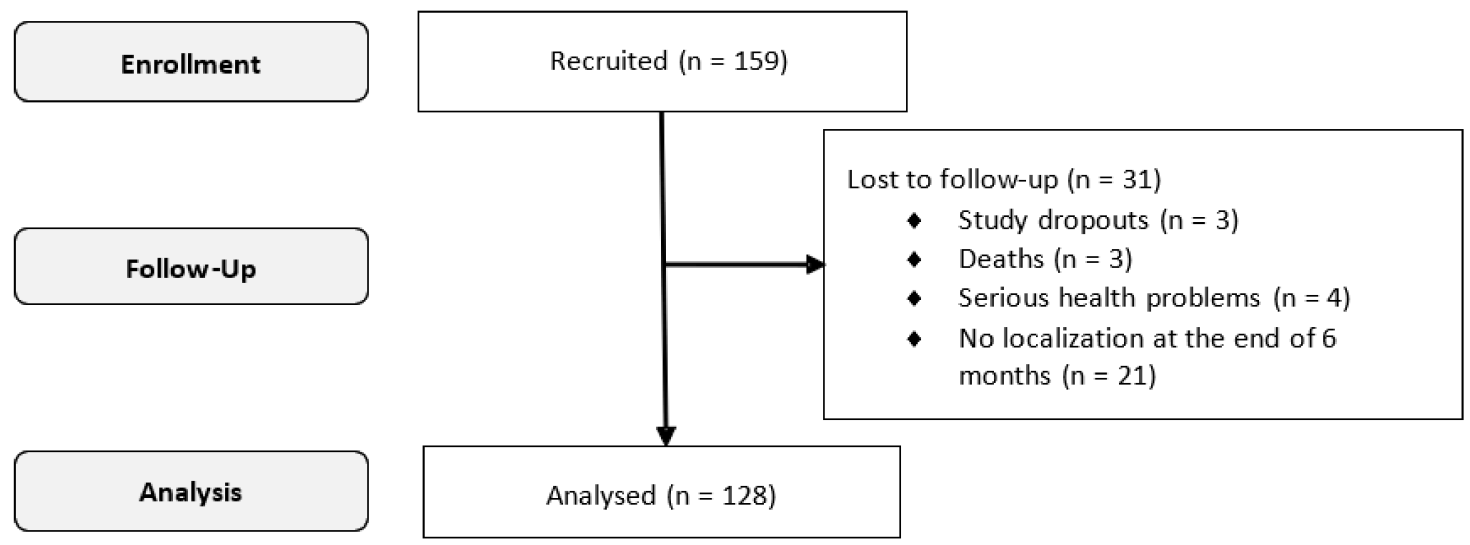

Figure 1. Flowchart: progress of patients through the study.

Table 2. Socio-demographics and clinical characteristics of the sample.

\begin{tabular}{lc}
\hline Sex (\%) & $62(48.4 \%)$ \\
Women & $66(51.6 \%)$ \\
Men & $49(43 ; 61.5)$ \\
Age (median (p25; p75)) & \\
Type of stroke (\%) & $69(53.9 \%)$ \\
Ischaemic & $59(46.1 \%)$ \\
Haemorrhagic & \\
Affected hemibody (\%) & $57(44.3 \%)$ \\
Left & $59(46.1 \%)$ \\
Right & $12(9.4 \%)$ \\
Both & $6(3 ; 9)$ \\
Time after stroke (months) (median (p25; p75)) & \\
Employment situation (\%) & $1(0.8 \%)$ \\
Active & $10(7.8 \%)$ \\
Unemployed & $30(23.4 \%)$ \\
Retired & $87(68.0 \%)$ \\
Sick leave & \\
Comorbidities (\%) & $50(39.1 \%)$ \\
Arterial hypertension & $21(16.4 \%)$ \\
Diabetes & $37(28.9 \%)$ \\
Other & \\
Family situation (\%) & $119(92.9 \%)$ \\
Lives alone & $1(0.8 \%)$ \\
Institutionalized & $8(6.3 \%)$ \\
BI & $64.7(31.20)$ \\
mRS (median (p25; p75)) & $4(2.5 ; 4)$ \\
\hline Barty & \\
\hline
\end{tabular}

BI: Barthel Index; mRS: modified Rankin Scale.

During the 6-month follow-up period, the results of each domain of the Spanish version of NEWSQOL showed improvement in terms of the mean score (SD), as well as the overall scores of the BI and the mRS (Table 3).

Correlation was demonstrated by the score changes of each domain of the Spanish version of NEWSQOL and the measures considered anchor criteria (Table 4). Spearman's correlation coefficient showed a statistically significant correlation for the results of each of the domains of the Spanish version of the NEWSQOL questionnaire with the BI, except the domains of sleep and fatigue. A strong correlation was shown with the dimensions of mobility $(\mathrm{r}=-0.883 ; p<0.01)$ and limitation for ADL $(\mathrm{r}=-0.808 ; p<0.01)$ and moderate correlation with the dimensions of feelings $(\mathrm{r}=-0.382 ; p<0.01)$, interpersonal relationships $(\mathrm{r}=-0.251 ; p<0.01)$, communication $(\mathrm{r}=-0.277 ; p<0.01)$ and vision $(\mathrm{r}=-0.197 ; p<0.01)$. 
The correlation was low for pain $(\mathrm{r}=-0.146 ; p<0.05)$, cognition $(\mathrm{r}=-0.184 ; p<0.05)$ and emotion $(\mathrm{r}=-0.322 ; p<0.05)$.

Table 3. Mean change in scores of the Spanish version of the NEWSQOL questionnaire, BI and mRS.

\begin{tabular}{|c|c|c|c|c|c|}
\hline $\begin{array}{l}\text { NEWSQOL } \\
(\mathrm{n}=128)\end{array}$ & $\begin{array}{l}\text { Pretreatment } \\
\text { Mean Score }\end{array}$ & SD & $\begin{array}{l}\text { Posttreatment } \\
\text { Mean Score }\end{array}$ & SD & $\begin{array}{c}p \\
\text { (Wilcoxon Test) }\end{array}$ \\
\hline Mobility & 15.7 & 8.8 & 9.8 & 8.4 & 0.000 \\
\hline ADL/self-care & 15.8 & 6.9 & 10.6 & 7.9 & 0.000 \\
\hline Pain/sensation & 2.1 & 2.4 & 1.4 & 1.8 & 0.000 \\
\hline Vision & 2.1 & 1.9 & 1.7 & 1.7 & 0.006 \\
\hline Cognition & 6.0 & 4.6 & 4.6 & 4.3 & 0.000 \\
\hline Communication & 5.8 & 4.1 & 4.3 & 3.8 & 0.000 \\
\hline Feelings & 14.7 & 4.3 & 13.0 & 4.8 & 0.000 \\
\hline Interpersonal relationships & 4.0 & 4.1 & 3.6 & 3.9 & 0.120 \\
\hline Emotion & 6.0 & 3.1 & 4.7 & 2.8 & 0.000 \\
\hline Sleep & 6.4 & 4.9 & 5.8 & 5.1 & 0.073 \\
\hline Fatigue & 2.9 & 2.6 & 2.3 & 2.5 & 0.002 \\
\hline \multirow[t]{2}{*}{ Barthel Index } & 64.7 & 31.2 & 77.8 & 27.1 & 0.000 \\
\hline & $\begin{array}{l}\text { Pretreatment } \\
\text { Mean Score }\end{array}$ & IQR & $\begin{array}{l}\text { Posttreatment } \\
\text { Mean Score }\end{array}$ & IQR & \\
\hline $\begin{array}{l}\text { Modified Rankin Scale } \\
\text { Median (p25; p75) }\end{array}$ & 4 & $2.5 ; 4$ & 2 & $1 ; 4$ & 0.000 \\
\hline
\end{tabular}

ADL: activities of daily living; SD: standard deviation; IQR: interquartile range.

Table 4. Correlation between change scores of studied measures (Spearman's correlation coefficient).

\begin{tabular}{ccc}
\hline Domain of NEWSQOL & BI & mRS \\
\hline Mobility & $-0.883^{* *}$ & $0.871^{* *}$ \\
ADL/self-care & $-0.808^{* *}$ & $0.770^{* *}$ \\
Pain/sensation & $-0.146^{*}$ & $0.244^{* *}$ \\
Vision & $-0.197^{* *}$ & $0.186^{* *}$ \\
Cognition & $-0.184^{* *}$ & $0.207^{* *}$ \\
Communication & $-0.277^{* *}$ & $0.240^{* *}$ \\
Feelings & $-0.382^{* *}$ & $0.469^{* *}$ \\
Interpersonal relationships & $-0.251^{* *}$ & $0.305^{* *}$ \\
Emotion & $-0.322^{*}$ & $0.255^{*}$ \\
Sleep & $-0.170^{*}$ & $-0.041^{* *}$ \\
Fatigue & -0.151 & $0.218^{* *}$ \\
\hline
\end{tabular}

mRS: modified Rankin Scale; BI: Barthel Index; ADL: activities of daily living. ${ }^{* *} p \leq 0.01{ }^{*} p \leq 0.05$.

In relation to the $\mathrm{mRS}$, there was a high correlation with the dimensions of mobility $(\mathrm{r}=0.871 ; p<0.01)$, ADL $(\mathrm{r}=0.770 ; p<0.01)$ and feelings $(\mathrm{r}=0.469 ; p<0.01)$. The correlation was moderate with dimensions of pain $(\mathrm{r}=0.244 ; p<0.01)$, cognition $(\mathrm{r}=0.207 ; p<0.01)$, interpersonal relationships $(\mathrm{r}=0.305 ; p<0.01)$, communication $(\mathrm{r}=0.240 ; p<0.01)$, vision $(\mathrm{r}=0.186 ; p<0.01)$ and fatigue $(\mathrm{r}=0.218 ; p<0.01)$. It showed no correlation with the domains of sleep and emotion.

Regarding mRS scores, $75 \%$ of the patients improved (96 responders) compared to the data of the BI as anchor criteria, where $49 \%$ patients improved (63 responders), and any of them suffered deterioration. Nevertheless, there was a percentage of $25 \%$ in the case of the $\mathrm{mRS}$ and $51 \%$ in the case of the BI where the patients' improvement did not reach the pre-established levels (nonresponders). Table 5 shows the results of each domain of the Spanish version of NEWSQOL for each subgroup and for each of the external criteria, $\mathrm{mRS}$ and BI. In the analysis based on anchor criteria, the values of both the ES and the SRM were higher either for the average change or for the change difference. For the Spanish version of NEWSQOL, the average change, in relation to the BI, showed a change in every domain and a correlation was established between the magnitude of average change and 
the statistics associated with responsiveness. The same pattern can could observed when the mRS data were used as the anchor criteria.

Table 5. Responsiveness statistics for the Spanish version of NEWSQOL and clinical measures by external criteria.

\begin{tabular}{|c|c|c|c|c|c|c|c|c|}
\hline \multirow[b]{2}{*}{$\begin{array}{l}\text { NEWSQOL } \\
\text { Domain }\end{array}$} & \multicolumn{3}{|c|}{ BI-Based External Criterion } & \multicolumn{3}{|c|}{ mRS-Based External Criterion } & \multirow[b]{2}{*}{$\begin{array}{l}\text { Effect Size } \\
\text { (ES) }\end{array}$} & \multirow[b]{2}{*}{$\begin{array}{c}\text { Standardized } \\
\text { Response } \\
\text { Mean (SRM) }\end{array}$} \\
\hline & $\begin{array}{l}\text { Average } \\
\text { Change }\end{array}$ & $\begin{array}{c}\text { Minimum } \\
\text { Change } \\
\text { Detectable }\end{array}$ & $\begin{array}{c}\text { Change } \\
\text { Difference }\end{array}$ & $\begin{array}{l}\text { Average } \\
\text { Change }\end{array}$ & $\begin{array}{c}\text { Minimum } \\
\text { Change } \\
\text { Detectable }\end{array}$ & $\begin{array}{l}\text { Change } \\
\text { Difference }\end{array}$ & & \\
\hline Mobility & $\begin{array}{c}\mathbf{n}=63 \\
-8.7\end{array}$ & $\begin{array}{c}\mathbf{n}=\mathbf{6 5} \\
-4.1\end{array}$ & $\begin{array}{c}\mathbf{n}=\mathbf{1 2 8} \\
-5.5\end{array}$ & $\begin{array}{c}\mathbf{n}=\mathbf{9 6} \\
-6.8\end{array}$ & $\begin{array}{c}\mathbf{n}=32 \\
-4.1\end{array}$ & $\begin{array}{c}\mathbf{n}=\mathbf{1 2 8} \\
-4.2\end{array}$ & $\begin{array}{c}\mathbf{n}=\mathbf{1 2 8} \\
0.66\end{array}$ & $\begin{array}{c}\mathbf{n}=\mathbf{1 2 8} \\
0.92\end{array}$ \\
\hline $\mathrm{ADL} /$ self-care & -7.3 & -4.4 & -4.1 & -6.5 & -3.1 & -5.1 & 0.75 & 0.87 \\
\hline Pain/sensation & -0.9 & 1.2 & -0.3 & -0.6 & 2.2 & 0.8 & 0.33 & 0.37 \\
\hline Vision & -0.3 & 1.0 & -0.3 & -0.4 & 0.9 & 0.0 & 0.21 & 0.23 \\
\hline Cognition & -1.6 & 2.1 & -0.5 & $-1,5$ & 2.5 & -0.5 & 0.29 & 0.37 \\
\hline Communication & -1.9 & 1.9 & -0.6 & -1.7 & 2.1 & -0.5 & 0.38 & 0.61 \\
\hline Feelings & -2.1 & 2.6 & -0.6 & -1.9 & 3.2 & -0.4 & 0.41 & 0.41 \\
\hline $\begin{array}{l}\text { Interpersonal } \\
\text { relationships }\end{array}$ & -0.5 & 1.4 & 0.1 & -0.2 & 2.2 & 0.9 & 0.11 & 0.13 \\
\hline Emotion & -1.3 & 2.0 & 0.0 & -1.2 & 2.4 & 0.1 & 0.41 & 0.44 \\
\hline Sleep & -0.1 & 2.3 & 0.9 & -0.4 & 2.8 & 0.7 & 0.13 & 0.11 \\
\hline Fatigue & -1.1 & -0.8 & -0.9 & -0.7 & 1.3 & -0.3 & 0.25 & 0.25 \\
\hline
\end{tabular}

ADL: activities of daily living; BI: Barthel Index; mRS: modified Rankin Scale.

The correlation of both showed that the results had been modified, in all domains, between initial and final moments. Observing the average change and change difference, the results were higher for the average change, as expected, since it focuses specifically on responder patients. In the change difference were included responder and nonresponder patients, and it was observed that two domains, sleep and interpersonal relationships, were not modified, resulting in these domains being interpreted as non-responsive with the statistical methods of the ES and the SRM. The highest values in the average change and change difference corresponded with each other and with the results of the ES and the SRM that indicated greater responsiveness to change.

\section{Discussion}

As far as the authors know, this is the first study for assessing the responsiveness of NEWSQOL since its development in 2004 [24]. This is not an isolated phenomenon; there are other quality-of-life (QoL) questionnaires widely used in post-stroke patients, both in clinical practice and in research studies that are culturally adapted to other languages other than the original where responsiveness is not studied either [38].

There is consensus among researchers that the effectiveness of a therapeutic intervention is important to measure it not only by survival time but also by the QoL perceived by the subject during that time. However, the lack of specific instruments, with psychometric properties studied rigorously, has been a constant inconvenience when working with poststroke patients [39]. Therefore, clinicians try to choose the best option among the different instruments to evaluate patients' perception about their health status changes. In addition, the selection and responsiveness of an instrument that best suits the characteristics of the disease or the pathological process is also important. Responsiveness is suggested as a basic criterion for the choice of instrument to be used when assessing a therapeutic intervention [40], although there is currently no consensus in the literature on the concept of responsiveness to change [27]. There are different statistical methods to evaluate this psychometric property, but no gold standard has been determined for a significant change in the QoL of post-stoke patients. It is most advisable to use multiple change criteria based on clinical anchors [26].

The sample size of this study was bigger than the ones in most measurement instrument validation studies on post-stroke patients. The clinical and socio-demographic characteristics were similar to other validation studies [41-43]. All participants had suffered a stroke between 3 and 9 months before being included in the study, and this period is within the range frequently showed in other validation studies of instruments for measuring the QoL after suffering a stroke [44]. 
Most responsiveness studies of specific instruments for patients who have suffered a stroke use a single statistical method, usually the ES or the SRM, and do not do so in relation to external measures [42,44-47], so it is not possible to assess in parallel whether these patients have undergone changes and the extent of those changes [26]. In this study, two anchor criteria were used; on the one hand, the patients who had improved were identified, and on the other hand, those who had remained stable were identified. This classification was based on a measure of disability (mRS) and a measure of functional independence (BI). The comparison with an external measuring instrument may allow researchers to obtain more reliable results [26,43]. The authors chose the mRS and the BI as two of the most commonly used standard instruments for post-stroke patients [48] also used in responsiveness studies on other QoL instruments [42,44,47,49].

The results found in this study present similarities, but also differences with those found in other responsiveness studies. The Spanish version of the NEWSQOL questionnaire was able to detect the recovery of patients during a physical therapy intervention's 6-month follow-up period in most domains, except for sleep and interpersonal relationships. It showed marked responsiveness for the domains of mobility and ADL, moderate responsiveness for communication and mild responsiveness for the domains of pain, vision, cognition, feelings, emotion and fatigue. Comparing responsiveness to other QoL-specific measurement instruments for stroke, the Escala de calidad de vida para el Ictus (ECVI38) [39] showed between mild and marked responsiveness, although it does not include the domains of pain, vision, sleep and fatigue, unlike NEWSQOL. The Danish version of the Stroke-Specific Quality of Life scale (SS-QOL) [47] showed mild-to-moderate responsiveness for most domains, except for the domains of personality, energy, upper extremity function and thinking, which were non-responsive. This scale does not include domains of pain, feelings, emotions and sleep. In the French version of the SS-QOL, 9 of the 12 domains showed mild-to-moderate responsiveness and only the energy domain was markedly responsive according to the SRM but not the ES [41]. HRQOLISP-40 showed marked global responsiveness within the physical sphere but not in the other domains [42]. The Stroke and Aphasia Quality of Life Scale-39 (SA-QOL), Singaporean version, showed mild responsiveness globally, and the changes were only significant for patients without aphasia [44].

Regarding generic HRQoL measures, two of the most commonly used in stroke trials are SF-36 and SF-12. SF-12 showed mild responsiveness for the physical component and moderate responsiveness for the mental component in a study that examined the responsiveness among stroke patients [50]. In some studies carried out with post-stroke patients, EuroQol 5 dimensions 5 Levels (EQ-5D-5L) was used to measure the QoL, and it showed moderate responsiveness in the global score. The study was limited to responders, avoiding nonresponders [26,51]. Generic QoL measures are common features in many stroke studies despite the disadvantage that most of such measures are less likely to assess aspects of life that have importance for post-stroke patients, such as fatigue, sleep, cognition, communication, feelings, emotions, vision and interpersonal relationships. These findings support some statements that generic QoL measures are less responsive to change compared to stroke-specific ones [52].

The fact that a measuring instrument is responsive is of vital importance for studies in which there is a special interest in patients' evolution over time and comparing therapeutic interventions about the patients' perception about their health status-hence the importance of not using instruments that merely assess isolated aspects of recovery or do not allow for the inclusion of the entire population. NEWSQOL is different from others questionnaires because it includes domains of vision, cognition and communication and it can used for patients with ischaemic or haemorrhagic stroke and motor aphasia.

As a limitation, we did not make any distinction between "some" and "big" changes" of the scores. 


\section{Conclusions}

In conclusion, the Spanish version of NEWSQOL showed between marked and mild responsiveness to measure the perception of the QoL in post-stroke patients who received a physical therapy intervention for 6 months. Therefore, its use can be suitable for evaluation studies, clinical trials and clinical practice.

Supplementary Materials: The following are available online at https://www.mdpi.com/article/ 10.3390/ijerph181910034/s1. Spanish version of NEWSQOL.

Author Contributions: Conceptualization, C.S.-V. and T.G.-I.; methodology, C.S.-V. and A.M.-G.; formal analysis, C.S.-V., V.C.-F. and A.M.-G.; investigation, C.S.-V., C.G.-A. and S.P.-d.-C.; writing - original draft preparation, C.S.-V., S.P.-d.-C. and V.C.-F.; writing-review and editing, C.S.-V., S.P.-d.-C. and V.C.-F. All authors have read and agreed to the published version of the manuscript.

Funding: The authors received no financial support for the research, authorship and/or publication of this article.

Institutional Review Board Statement: The study was conducted according to the guidelines of the Declaration of Helsinki, and approved by the Ramon and Cajal University Hospital Research Ethics Committee in Madrid, Spain (protocol no. 120/11. Date of approval 14/06/2011).

Informed Consent Statement: Informed consent was obtained from all subjects involved in the study.

Data Availability Statement: The data presented in this study are available on request from the corresponding author. The data are not publicly available due to the ethical declaration issue.

Acknowledgments: The authors thank all patients who participated in this study.

Conflicts of Interest: The authors declare no potential conflicts of interest with respect to the research, authorship and/or publication of this article.

\section{References}

1. Azevêdo da Costa, F.; Araujo da Silva, D.; da Rocha, V. Condición funcional de los pacientes tras un accidente vascular encefálico. Rev. Neurol. 2006, 42, 591-595. [CrossRef]

2. Van Meijeren-Pont, W.; Volker, G.; Vliet Vlieland, T.; Goossens, P. Comparison of the responsiveness of the Utrecht Scale for Evaluation of Rehabilitation (USER) and the Barthel Index in stroke patients. Clin. Rehabil. 2019, 33, 1672-1681. [CrossRef] [PubMed]

3. Hess, D.C.; Eldahshan, W.; Rutkowski, E. COVID-19-related stroke. Transl. Stroke Res. 2020, 11, 322-325. [CrossRef] [PubMed]

4. Tan, Y.K.; Goh, C.; Leow, A.S.; Tambyah, P.A.; Ang, A.; Yap, E.S.; Tu, T.M.; Sharma, V.K.; Yeo, L.L.; Chan, B.P.; et al. COVID-19 and ischemic stroke: A systematic review and meta-summary of the literature. J. Thromb. Thrombolysis 2020, 50, 587-595. [CrossRef] [PubMed]

5. Kessner, S.S.; Bingel, U.; Thomalla, G. Somatosensory deficits after stroke: A scoping review. Top. Stroke Rehabil. 2016, 23, $136-146$. [CrossRef]

6. Moran, G.M.; Fletcher, B.; Feltham, M.G.; Calvert, M.; Sackley, C.; Marshall, T. Fatigue, psychological and cognitive impairment following transient ischaemic attack and minor stroke: A systematic review. Eur. J. Neurol. 2014, 21, 1258-1267. [CrossRef]

7. Pinter, D.; Enzinger, C.; Gattringer, T.; Eppinger, S.; Niederkorn, K.; Horner, S.; Fandler, S.; Kneihsl, M.; Krenn, K.; Bachmaier, G.; et al. Prevalence and short-term changes of cognitive dysfunction in young ischaemic stroke patients. Eur. J. Neurol. 2019, 26, 727-732. [CrossRef]

8. Baumann, M.; Couffignal, S.; Le Bihan, E.; Chau, N. Life satisfaction two-years after stroke onset: The effects of gender, sex occupational status, memory function and quality of life among stroke patients (NewsQol) and their family caregivers (WhoQol-bref) in Luxembourg. BMC Neurol. 2012, 12, 105. [CrossRef]

9. Hepworth, L.R.; Rowe, F.J; Harper, R.; Jarvis, K.; Shipman, T.; Rodgers, H. Patient reported outcome measures for visual impairment after stroke: A systematic review. Health Qual. Life Outcomes 2015, 13, 146. [CrossRef]

10. Dai, C.Y.; Liu, W.M.; Chen, S.W.; Yang, C.A.; Tung, Y.C.; Chou, L.W.; Lin, L.C. Anosognosia, neglect and quality of life of right hemisphere stroke survivors. Eur. J. Neurol. 2014, 21, 797-801. [CrossRef]

11. Dorňák, T.; Justanová, M.; Konvalinková, R.; Ǩíha, M.; Mužík, J.; Hoskovcová, M.; Srp, M.; Navrátilová, D.; Otruba, P.; Gál, O.; et al. Prevalence and evolution of spasticity in patients suffering from first-ever stroke with carotid origin: A prospective, longitudinal study. Eur. J. Neurol. 2019, 26, 880-886. [CrossRef]

12. Feyissa, A.M.; Hasan, T.F.; Meschia, J.F. Stroke-related epilepsy. Eur. J. Neurol. 2019, 26, 18-e3. [CrossRef]

13. Espárrago-Llorca, G.; Castilla-Guerra, L.; Fernández Moreno, M.C.; Ruiz Doblado, S.; Jiménez Hernández, M.D. Post-stroke depression: An update. Rev. Neurol. 2015, 30, 23-31. [CrossRef] 
14. Lima, R.R.; Rose, M.L.; Lima, H.N.; Cabral, N.L.; Silveira, N.C.; Massi, G.A. Prevalence of aphasia after stroke in a hospital population in southern Brazil: A retrospective cohort study. Top. Stroke Rehabil. 2020, 27, 215-223. [CrossRef]

15. Baumstarck, K.; Butzkueven, H.; Fernández, O.; Flachenecker, P.; Stecchi, S.; Idiman, E.; Pelletier, J.; Boucekine, M.; Auquier, P. Responsiveness of the Multiple Sclerosis International Quality of Life questionnaire to disability change: A longitudinal study. Health Qual. Life Outcomes 2013, 11, 127. [CrossRef]

16. Haacke, C.; Althaus, A.; Spottke, A.; Siebert, U.; Back, T.; Dodel, R. Long-term outcome after stroke: Evaluating health-related quality of life using utility measurements. Stroke 2006, 37, 193-198. [CrossRef]

17. Carod-Artal, F.J. Determining quality of life in stroke survivors. Expert Rev. Pharm. Outcomes Res. 2012, 12, 199-211. [CrossRef]

18. Sand, K.M.; Wilhelmsen, G.; Naess, H.; Midelfart, A.; Thomassen, L.; Hoff, J.M. Vision problems in ischaemic stroke patients: Effects on life quality and disability. Eur. J. Neurol. 2016, 23 (Suppl. 1), 1-7. [CrossRef]

19. Heikinheimo, T.; Chimbayo, D. Quality of life after first-ever stroke: An interview-based study from Blantyre, Malawi. Malawi Med. J. 2015, 27, 50-54. [CrossRef]

20. Arba, F.; Ali, M.; Quinn, T.J.; Hankey, G.J.; Lees, K.R.; Inzitari, D. Lacunar Infarcts, Depression, and Anxiety Symptoms One Year after Stroke. J. Stroke Cerebrovasc. Dis. 2016, 25, 831-834. [CrossRef]

21. KKatona, M.; Schmidt, R.; Schupp, W.; Graessel, E. Predictors of health-related quality of life in stroke patients after neurological inpatient rehabilitation: A prospective study. Health Qual. Life Outcomes 2015, 13, 58. [CrossRef]

22. Tidermark, J.; Bergström, G. Responsiveness of the EuroQol (EQ-5D) and the Nottingham Health Profile (NHP) in elderly patients with femoral neck fractures. Qual. Life Res. 2007, 16, 321-330. [CrossRef]

23. Carod-Artal, F.J. Escalas específicas para la evaluación de la calidad de vida en el ictus. Rev. Neurol. 2004, 39, 1052-1062.

24. Buck, D.; Jacoby, A.; Massey, A.; Steen, N.; Sharma, A.; Ford, G.A. Development and validation of NEWSQOL, the Newcastle Stroke-Specific Quality of Life Measure. Cerebrovasc. Dis. 2004, 17, 143-152. [CrossRef] [PubMed]

25. Soto-Vidal, C.; Pacheco-da-Costa, S.; Calvo-Fuente, V.; Fernández-Guinea, S.; González-Alted, C.; Gallego-Izquierdo, T. Validation of the Spanish Version of Newcastle Stroke-Specific Quality of Life Measure (NEWSQOL). Int. J. Environ. Res. Public Health 2020, 17, 4237. [CrossRef]

26. Golicki, D.; Niewada, M.; Karlińska, A.; Buczek, J.; Kobayashi, A.; Janssen, M.F.; Pickard, A.S. Comparing responsiveness of the EQ-5D-5L, EQ-5D-3L and EQ VAS in stroke patients. Qual. Life Res. 2015, 24, 1555-1563. [CrossRef]

27. García de Yébenes, M.J.; Rodríguez, F.; Carmona, L. Responsiveness of outcome measures. Reumatol. Clín. 2008, 4, $240-247$. [CrossRef]

28. Guyatt, G.H.; Feeny, D.H.; Patrick, D.L. Measuring health-related quality of life. Ann. Intern. Med 1993, 118, 622. [CrossRef]

29. De la Iglesia, J.; Herrero, R.; Vilches, M.; Taberné, C.; Colomer, C.; Luque, R. Adaptación y validación al castellano del cuestionario de Pfeiffer (SPMSQ) para detectar la existencia de deterioro cognitivo en personas mayores de 65 años. Med. Clin. 2001, 117, 129-134. [CrossRef]

30. Sanz, A.F.; Serrano, J.R.; Meza, H.T.; Moreno, J.M. Validación del cuestionario simplificado de la escala modificada Rankin (smRSq) telefónico en castellano. Neurología 2019, in press. [CrossRef]

31. Mahoney, F.; Barthel, D. Functional evaluation: The Barthel Index. Md. State Med. J. 1965, 14, 61-65.

32. Dromerick, A.W.; Edwards, D.F.; Diringer, M.N. Sensitivity to changes in disability after stroke: A comparison of four scales useful in clinical trials. J. Rehabil. Res. Dev. 2003, 40,1-8. [CrossRef]

33. Quinn, T.J.; Langhorne, P.; Stott, D.J. Barthel index for stroke trials: Development, properties, and application. Stroke 2011, 42, 1146-1151. [CrossRef]

34. Wyrwich, K.W.; Bullinger, M.; Aaronson, N.; Hays, R.D.; Patrick, D.L.; Symonds, T. Estimating clinically significant differences in quality of life outcomes. Qual. Life Res. 2005, 14, 285-295. [CrossRef]

35. Huybrechts, K.F.; Jaime Caro, J. The Barthel Index and modified Rankin Scale as prognostic tools for long-term outcomes after stroke: A qualitative review of the literature. Curr. Med. Res. Opin. 2007, 23, 1627-1636. [CrossRef]

36. Hsieh, Y.; Wang, C.; Wu, S.; Chen, P.; Sheu, C.; Hsieh, C. Establishing the minimal clinically important difference of the Barthel Index in stroke patients. Neurorehabil. Neural Repair 2007, 21, 233-238. [CrossRef] [PubMed]

37. Cohen, J. Statistical Power Analysis for the Behavioral Sciences, revised ed.; Academic Press: Cambridge, MA, USA, 2013.

38. Ahmadi, A.; Tohidast, S.A.; Mansuri, B.; Kamali, M.; Krishnan, G. Acceptability, reliability, and validity of the Stroke and Aphasia Quality of Life Scale-39 (SAQOL-39) across languages: A systematic review. Clin. Rehabil. 2017, 31, 1201-1214. [CrossRef]

39. Fernández-Concepción, O.; Ramírez-Pérez, E.; Álvarez, M.; Buergo-Zuáznabar, M. Validación de la escala de calidad de vida para el ictus (ECVI-38). Rev. Neurol. 2008, 46, 147-152. [CrossRef]

40. Sánchez, B.S.; Lacomba, M.T.; Brazález, B.N.; Téllez, E.C.; Da Costa, S.P.; Ortega, C.G. Responsiveness of the Spanish pelvic floor distress inventory and pelvic floor impact questionnaires short forms (PFDI-20 and PFIQ-7) in women with pelvic floor disorders. Eur. J. Obstet. Gynecol. Reprod. Biol. 2015, 190, 20-25. [CrossRef]

41. Legris, N.; Devilliers, H.; Daumas, A.; Carnet, D.; Charpy, J.P.; Bastable, P.; Giroud, M.; Bejot, Y. French validation of the stroke specific quality of life scale (SS-QOL). NeuroRehabilitation 2018, 42, 17-27. [CrossRef] [PubMed]

42. Vincent-Onabajo, G.O.; Owolabi, M.O.; Hamzat, T.K. Sensitivity and responsiveness of the health-related quality of life in stroke patients-40 (HRQOLISP-40) scale. Disabil. Rehabil. 2014, 36, 1014-1019. [CrossRef]

43. Hilari, K.; Lamping, D.L.; Smith, S.C.; Northcott, S.; Lamb, A.; Marshall, J. Psychometric properties of the Stroke and Aphasia Quality of Life Scale (SAQOL-39) in a generic stroke population. Clin. Rehabil. 2009, 23, 544-557. [CrossRef] 
44. Guo, Y.E.; Togher, L.; Power, E.; Heard, R.; Luo, N.; Yap, P.; Koh, G.C. Sensitivity to change and responsiveness of the Stroke and Aphasia Quality-of-Life Scale (SAQOL) in a Singapore stroke population. Aphasiology 2017, 31, 427-446. [CrossRef]

45. Chen, H.; Wu, C.; Lin, K.; Li, M.; Yu, H. Validity, reliability and responsiveness of a short version of the stroke-specific quality of life scale in patients receiving rehabilitation. J. Rehabil. Med. 2012, 44, 629-636. [CrossRef]

46. Lin, K.; Fu, T.; Wu, C.; Hsieh, Y.; Chen, C.; Lee, P. Psychometric comparisons of the Stroke Impact Scale 3.0 and Stroke-Specific Quality of Life Scale. Qual. Life Res. 2010, 19, 435-443. [CrossRef]

47. Muus, I.; Christensen, D.; Petzold, M.; Harder, I.; Johnsen, S.P.; Kirkevold, M.; Ringsberg, K.C. Responsiveness and sensitivity of the Stroke Specific Quality of Life Scale Danish version. Disabil. Rehabil. 2011, 33, 2425-2433. [CrossRef]

48. Quinn, T.; Dawson, J.; Walters, M.; Lees, K. Functional outcome measures in contemporary stroke trials. Int. J. Stroke 2009, 4, 200-205. [CrossRef]

49. Pickard, A.S.; Johnson, J.A.; Feeny, D.H. Responsiveness of generic health-related quality of life measures in stroke. Qual. Life Res. 2005, 14, 207-219. [CrossRef] [PubMed]

50. Muller-Nordhorn, J.; Nolte, C.H.; Rossnagel, K.; Jungehulsing, G.J.; Reich, A.; Roll, S.; Villringer, A.; Willich, S.N. Responsiveness to change of the SF-12 in patients with cerebrovascular disease. Biom. J. 2004, 46, 50. [CrossRef]

51. Chen, P.; Lin, K.; Liing, R.; Wu, C.; Chen, C.; Chang, K. Validity, responsiveness, and minimal clinically important difference of EQ-5D-5L in stroke patients undergoing rehabilitation. Qual. Life Res. 2016, 25, 1585-1596. [CrossRef]

52. Williams, L.S.; Weinberger, M.; Harris, L.E.; Clark, D.O.; Biller, J. Development of a stroke-specific quality of life scale. Stroke 1999, 30, 1362-1369. [CrossRef] [PubMed] 